\title{
Efficient development of practically usable thermo- photo sensitive genic male sterile lines in wheat through doubled haploid breeding
}

Hongsheng Li

Institute of Food Crops, Yunnan Academy of Agricultural Sciences https://orcid.org/0000-0002-96584754

Shaoxiang Li

Institute of Food Crops, Yunnan Academy of Agricultural Sciences

\section{Sedhom Abdelkhalik}

Field crops Research Institute, Agricultural Research Center Egypt

Armaghan Shahzad

National Institute for Genomics and Advanced Biotechnology, National Agricultural Research Center

Jian Gu

Institute of Food Crops, Yunnan Academy of Agricultural Sciences

Zhonghui Yang

Institute of Food Crops, Yunnan Academy of Agricultural Sciences

Mingliang Ding

Institute of Food Crops, Yunnan Academy of Agricultural Sciences

Kun Liu

Institute of Food Crops, Yunnan Academy of Agricultural Sciences

Hong Zhao

Institute of Food Crops, Yunnan Academy of Agricultural Sciences

Mujun Yang ( $\square$ kmyangmj@163.com )

https://orcid.org/0000-0001-8400-548X

\section{Research article}

Keywords: Hybrid wheat, Two lines system, thermo, photo sensitive genic male sterile line, doubled haploid, wheat, maize

Posted Date: September 30th, 2019

DOI: https://doi.org/10.21203/rs.2.15367/v1 
License: (c) (i) This work is licensed under a Creative Commons Attribution 4.0 International License. Read Full License

Version of Record: A version of this preprint was published at BMC Plant Biology on June 1st, 2020. See the published version at https://doi.org/10.1186/s12870-020-02458-5. 


\section{Abstract}

Two-line hybrid wheat system using thermo-photo sensitive genic male sterility (TPSGMS) is now a dominant and promising approach of wheat heterosis utilization in China. However, few TPSGMS lines available for practical application have always been a bottleneck affecting the efficiency of creating hybrids with strong heterosis since its establishment in 1992. This study aimed to improve the efficiency of developing TPSGMS lines by doubled haploid (DH) breeding. F $1 \mathrm{~s}$ and selected $\mathrm{F} 2$ and $\mathrm{F} 3$ sterile plants from 8 crosses made with 2 commercial TPSGMS lines K78S and K456S were used to produce DH lines by wheat $\times$ maize system. 24 elite sterile lines possessing stable sterility, good outcrossing and yield potentials, resistance to yellow rust and powdery mildew, and desirable plant height $(50-60 \mathrm{~cm})$ were obtained within 4 years. 20 out of 24 elite lines that performed stable sterility in tests of two or three years and high outcrossing rate $(>70 \%)$ under open pollination, will be used for hybrid breeding later. The percentage of selected sterile lines in total tested $\mathrm{DH}$ lines produced from filial generations was in the order of $\mathrm{F} 3>\mathrm{F} 2>\mathrm{F} 1$ for sterility, and F $2>\mathrm{F} 3>\mathrm{F} 1$ for elite lines in this study, thus producing DHs from $\mathrm{F} 2$ generation appeared to be the better choice considering the balance of overall breeding efficiency and time saving. This study verified that combining $\mathrm{DH}$ techniques with conventional breeding would be an efficient strategy for developing practically usable wheat TPSGMS lines, both in number and time saving.

\section{Introduction}

Wheat is planted $\sim 220$ million hectares annually in the world contributing a great deal in food security. Heterosis utilization in wheat is considered to be one of the effective ways for further increasing yield potential and stability (Mühleisen et al. 2013, Singh et al. 2015, Murai et al. 2016). Though beneficial, it remains a worldwide problem that researchers have been trying to resolve for more than half a century, especially in efficiency of developing hybrids with super heterosis and producing hybrid seeds (Singh et al. 2015, Boeven et al. 2018).

Unlike hybrid wheat systems based on cytoplasmic male sterility (CMS, Wilson et al.1962) and photoperiod-sensitive cytoplasmic male sterility (PCMS, Murai et al. 1993), the two-line hybrid wheat system using thermo-photo sensitive genic male sterility (TPSGMS) is a new way of wheat heterosis utilization in China. The TPSGMS line is characterized as being sterile under low-temperature and shortday for hybrid seed production, and fertile under high-temperature and long-day for self propagation. Therefore, this system does not need the maintainer line, with wide resources of restorers and simple hybrid seed production procedures (Tan et al. 1992, Ji et al. 2004, Zhao 2010). From 2002 to 2018, out of 20 hybrid varieties released in China, 14 were from TPSGMS two-line system and applied in China with yield increase at 10-15\%, especially in pool lands (Xiao 2014, Tao et al. 2017, www.stdaily.com). Meanwhile, encouraging multi-location demonstrations regarding productivity have been achieved in Vietnam, where "Yunza" hybrid varieties performed much better than local inbred cultivars in yield, drought tolerance and fertilizer input (chinagrain.cn). However, 14 TPSGMS-based hybrid varieties only held $\sim 0.5 \%$ of total 2691 wheat varieties released in China from 2002 to 2018 (www.seedchina.com.cn), and few hybrid varieties were applied in main producing areas such as Yellow-Huai River wheat zone of 
China, where inbred varieties perform well in yield while most hybrid varieties available did not exhibit enough yield superiority. An important cause for such situation is that less than ten TPSGMS lines across China were practically capable both for developing hybrid variety with strong heterosis and efficiently producing qualified hybrid seeds during past 20 years, which greatly decreased the opportunities and efficiency of creating superior hybrids even ten thousands of restorers were available and test-crossed. Therefore, more practically usable TPSGMS lines should be developed and utilized.

Doubled haploid $(\mathrm{DH})$ techniques that can make any segregating material homozygous in one generation, have been widely applied in crop breeding to improve the efficiency of selection and accelerate the breeding process (Tadesse et al. 2012; Muqaddasi et al. 2017; Song et al. 2017; Kelliher et al 2019; Wang et al. 2019). Wheat $\times$ maize induced wheat doubled haploid is currently one of the most matured haploid breeding techniques in wheat with advantages of stable induction rate and few genotypic restrictions (Suenaga et al. 1989; Niu et al. 2014), could be helpful for improving development of wheat TPSGMS lines.

The present study aimed to establish an efficient strategy of developing wheat TPSGMS lines by evaluating the breeding efficiency using wheat $\times$ maize based DH technique in TPSGMS line breeding program with sterile materials belonging to different filial generations.

\section{Materials and methods}

\section{Materials And Methods \\ Plant materials}

Two TPSGMS lines and five semi-sterile advanced lines of wheat used in the study are listed in Table1. A maize variety "Baitiannuo" was used as pollen donor in DH production. All wheat and maize materials were bred by Institute of Food Crops, Yunnan Academy of Agricultural Sciences, Kunming, China.

\section{Cross-making and DH production}

Wheat materials were late sown in January 2014 to make semi-sterile materials fertile for cross-making at Kunming, Yunnan province, China $\left(25^{\circ} 02^{\prime} \mathrm{N}, 102^{\circ} 42^{\prime} \mathrm{E}\right.$, altitude $\left.1960 \mathrm{~m}\right)$, where spring wheat could be planted and harvested all the year round. Maize sowing (April) began two months before wheat sowing (June) in three different sowing dates with 14 days intervals.

The crosses made and subsequent treatments are summarized in Table 2.

Before producing doubled haploids, sterile plants segregated from $F_{1}$ and $F_{2}$ generations were selected according to performances in sterility, out-crossing potential including glume opening and stigma exertion ( $\mathrm{Li}$ et al. 2015), plant height (50-60 cm), resistance to yellow rust and powdery mildew, tillering 
ability and yield potential. Seeds of sterile plants were harvested from regenerated tillers by cutting off all spikes of sterile plants plus intensive irrigation and fertilization.

\section{Method of producing DHs}

For DH production, an improved protocol (Gu et al. 2008, 2012) was adopted. Emasculated wheat spikes were pollinated with maize pollens, pollinated tillers were cut 24 hours after pollination and sprayed with 2, 4-D at $100 \mathrm{ppm}$, then cultured in growth chambers with nutrition solution for 14 days. Embryos were aseptically dissected from caryopses and cultured on $1 / 2 \mathrm{MS}$ medium under darkness at $24-25^{\circ} \mathrm{C}$ until germination, then moved to culture room with 10 hours photoperiod and the same temperature. After seedlings produced tillers, colchicine was used to induce doubling of chromosomes, treated seedlings were transplanted into pots to grow until booting stage, then moved into greenhouse for 15 days, keeping temperature $>20^{\circ} \mathrm{C}$ to assure doubled plants fertile. All plants were bagged before flowering and harvested one by one.

\section{Sterility evaluation of DH lines}

DH lines obtained during 2015-2017 were first evaluated in a two-sowing test, qualified lines in sterility were kept for further evaluation. As usual, the $1^{\text {st }}$ and $2^{\text {nd }}$ sowing dates were on Oct.15 and Nov. 20, respectively. At least 10 spikes per line in each sowing were randomly bagged before flowering to measure the seed setting rate and out-crossing potential, other important traits such as disease resistances and yield potential were also recorded. Selected lines in 2015/2016 and 2016/2017 were again evaluated in 2016/2017 and 2017/2018. We also conducted a ten-sowing assessment from Oct. 22,2017 to Dec. 24 with interval of 7 days for elite lines of $F_{1}$ generation that qualified in last two-year tests. K78S was used as check in all tests. The seed setting rate (SSR) was calculated following Yang et al. (2006):

$\operatorname{SSR}(\%)=g n /((\operatorname{sn} \times 2) \times 100$

Where $g n$ means the grain number of bagged spikes, $s n$ the spikelet numbers. A TPSGMS line with SSR < $5 \%$ is recognized as highly sterile and qualified for hybrid seed production (Yang et al. 2006).

\section{Out-crossing test of DH lines}

During winter sowing of 2018/2019, 20 elite $\mathrm{DH}$ sterile lines derived from $\mathrm{F}_{1}$ and from $\mathrm{F}_{2}$ generations were separately planted as 10 rows in a plot of $1 \mathrm{~m} \times 2.5 \mathrm{~m}$ surrounding with $\sim 600$ restorers. Open pollination was aided by natural wind at grade 3-6 that always has in Yunnan throughout wheat growing seasons. 20 randomly bagged and open pollinated spikes were separately harvested to measure the selffertility and out-crossing rate (OR) of sterile lines using formula as follow: 
$O R(\%)=(u g n-b g n) /(/(s n \times 2) \times 100$

Where ugn and bgn separately denote un-bagged and bagged grain numbers at two basal florets of each spikelet, $s n$ the spikelet numbers per spike.

Data of temperature during 2016-2018 were collected from a data-logger 'HUATO S100-TH' in thermometer screen near the field, and daylengths from the meteorological station of Kunming.

\section{Results}

\section{Production of $\mathrm{DH}$ lines}

During summer sowings of 2014-2016, we produced DHs with four $F_{1} s$ and sterile plants selected from $F_{1} s$ and $F_{2} s$ through wheat maize (Table 2). A total of $920 \mathrm{DH}$ lines were obtained from all eight crosses (Table 3). The average embryo rate, seedling rate of embryos and chromosome doubling rate of seedlings were $36.76 \%, 62.65 \%$ and $86.42 \%$, respectively, exhibiting good efficiency in DH production though most parameters were affected by differences in combinations or genotypes. In Dec. 2016, a serious frost damaged some doubling treated plants that were heading, resulting in partial failure to obtain $\mathrm{DH}$ seeds.

Temperate climate at Kunming especially from May to Oct. allows planting springness and vernalized winterness wheat materials throughout the year under natural conditions here (Fig. 1), which facilitates efficient and mass production of wheat DHs by wheat maize crosses because plenty of fresh pollens are available from naturally and repeatedly planted maize from late Apr. to early Nov. (Gu et al. 2006, 2008, 2012; Liu et al. 2016, Ding et al. 2017).

\section{Selection of candidate DH sterile lines}

All $920 \mathrm{DH}$ lines produced from $\mathrm{F}_{1}, \mathrm{~F}_{2}$ and $\mathrm{F}_{3}$ generations were separately tested in sterility during 20162018. Among them, $295 \mathrm{DH}$ lines showing normal seed set were excluded from further identification, mainly from $F_{1}$ generations as expected. In $1^{\text {st }}$ and $2^{\text {nd }}$ sowings, 210 and $66 \mathrm{DH}$ lines had seed setting rate less than $5 \%$, accounting for $33.60 \%$ and $10.56 \%$ of remaining 625 lines tested, respectively. 41 (6.56\%) DH lines showed seed setting rate less than $5 \%$ in both sowings (Table 3, Table 4, Fig. 2).

In southwest of China, wheat is normally sowed from middle Oct. to early Nov., thus a TPSGMS line with seed setting rate $<5 \%$ in both sowings (from Oct. 15 to Nov. 20) has been able to meet the demand for safe production of hybrid seeds. While when keeping in view other desired traits of out-crossing rate ( $\geq 70 \%)$, disease resistance (to stripe rust, powdery mildew), plant height (50-60 cm), tillering and spike formation ability, 24 elite lines were finally selected from 41 lines above (Table 3, Table 4).

The sensitive period that causes TPSGMS lines to alter fertility, would be the date from middle to late Feb. for $1^{\text {st }}$ sown (Oct. 15) lines, and late Mar. to early Apr. for $2^{\text {nd }}$ sown (Nov. 20) lines. Consequently, during 
sensitive periods, $1^{\text {st }}$ sown lines would have low temperature and short-day to fully exhibit sterility, while $2^{\text {nd }}$ sown lines would have relatively higher temperature and longer daylength that make most spikes sterile and some axillary spikes partially fertile to produce a few seeds for propagation (Fig.1). To our experiences, TPSGMS lines that perform $100 \%$ sterile in $2^{\text {nd }}$ sowing are usually stable in sterility but difficult in propagation, not suitable for practical application.

\section{Sterility identification of $\mathrm{DH}$ lines derived from $\mathrm{F}_{1}$ generation}

Ten elite DH sterile lines derived from $F_{1}$ were repeatedly tested during 2016-2018. In 2016/2017, the seed setting rates of all lines were 0 in $1^{\text {st }}$ sowing, and $2.98-4.87 \%$ in the $2^{\text {nd }}$ sowing (Table 5 ). In further ten sowings of $2017 / 2018$, the seed setting rates of ten elite lines were $<1 \%$ from $1^{\text {st }}$ to $3^{\text {rd }}$ sowings (Oct.22-Nov. 5), $<5 \%$ till the $5^{\text {th }}$ sowing (Nov. 19), and $\geq 50 \%$ in the $10^{\text {th }}$ sowing (Dec. 24 ), suggesting sowings before Nov. 5 and Nov. 19 were separately the optimum and suitable times for hybrid seed production while after Dec. 24 the suitable time for propagation of these sterile lines (Figure 3).

During 2016-2018, ten elite TPSGMS lines derived from $F_{1}$ generation showed highly or $100 \%$ sterility in three consecutive years when sown from Oct. 15 to Nov. 5, although the average temperatures fluctuated from $12^{\circ} \mathrm{C}$ to $15^{\circ} \mathrm{C}$ during their sensitive periods from the second half Feb. to the first half Mar. (Fig.1), will be utilized in hybrid breeding later.

\section{Sterility evaluation of sterile lines derived from $\mathrm{F}_{2}$ generation}

Ten selected lines in 2016/2017 derived from $F_{2}$ were tested again in winter sowing of $2017 / 2018$. The seed setting rates of all lines were 0 in $1^{\text {st }}$ sowing, and $1.99-4.04 \%$ in $2^{\text {nd }}$ sowing (Table 6 ). All elite lines performed stably in sterility during two-year cycles, will be planted as ten sowings for further identification in sterility, suitable times for hybrid seed production and propagation. Meanwhile, preliminary test-crosses will be conducted with these lines.

\section{Evaluation of out-crossing}

In winter sowing of 2018/2019, 20 elite TPSGMS lines derived from $F_{1}$ and $F_{2}$ generations showed $82.87 \%$ of out-crossing rates in average, ranging from $70.46 \%$ to $93.90 \%$. There were 13 lines including 8 derived from $\mathrm{F}_{2}$ with out-crossing rate $>80 \%$, 4 lines between $75 \%$ and $80 \%$, and 3 lines between $70 \%$ and $75 \%$ (Table 7). All 20 lines showed good out-crossing ability even only one round of selection was done after $\mathrm{DH}$ production, because doubled haploids had 'fixed' the trait, which confirmed our previous results (Li et al, 2015). However, more lines derived from $F_{2}$ appear to have better out-crossing ability $(>80 \%)$ compared with that from $\mathrm{F}_{1}$, suggesting one more round of selection before $\mathrm{DH}$ production helped to further concentrate the target trait. In fact, the results of out-crossing rates here were obtained by 
pollination with nearly saturated pollen supply, and need to be further assessed in practical hybrid seed production.

\section{Breeding efficiency of producing DHs from different generations}

According to seed setting rates $<5 \%$ in both sowings, we selected $41 \mathrm{DH}$ sterile lines including 13,15 , and 13 lines separately derived from $F_{1}, F_{2}$ and $F_{3}$ generations, with breeding efficiency (percentage of selected $\mathrm{DH}$ lines in total $\mathrm{DH}$ lines tested) of $4.14 \%, 7.35 \%$ and $12.15 \%$ in $\mathrm{F}_{1}, \mathrm{~F}_{2}$ and $\mathrm{F}_{3}$, respectively. When out-crossing ability, resistance and other desired traits were further considered, 24 elite lines the overall breeding efficiency in $F_{1}, F_{2}$ and $F_{3}$ were $3.18 \%, 4.90 \%$ and $3.74 \%$, respectively (Table 4 ). Therefore, the trend of breeding efficiency in sterility was $F_{3}>F_{2}>F_{1}$, while the overall breeding efficiency for elite lines was in the order of $F_{2}>F_{3}>F_{1}$.

\section{Discussion}

Utilization of malesterility is the basis of commercial application of hybrid wheat. It's common for all genetically controlled sterility systems that the more sterile lines capable for commercial application are used for testcross, the more opportunities of creating hybrids with super heterosis would have. Though the TPSGMS based two-line hybrid system was established as early as 1990s (Tan et al. 1992, Zhao et al. 1999), but only several TPSGMS lines capable for commercial usage were developed and utilized from north to south wheat zones of China up to now. Pedigree method is commonly used in developing TPSGMS lines (Zhang et al. 1999, Gu et al. 2002), however, there are some difficulties hindering the breeding efficiency. The sterility of TPSGMS line is controlled by recessive nuclear major genes or plus minor genes (Tan et al. 1992, Guo et al. 2006, Yang et al. 2006, Zhang et al. 2007, Dong et al. 2012), causing a very low proportion of highly sterile plants in segregating population, especially in $\mathrm{F}_{2} \mathrm{~s}$ derived from crosses between sterile lines and normal fertile lines. When other important traits like outcrossing ability, plant height, yield potential, disease resistance, etc. are considered together, the breeding efficiency would become extremely low. Theoretically, the probability of homozygous recessive individuals in $F_{2}$ population is $1 / 4^{n}$, while that in $\mathrm{DH}$ population produced from $\mathrm{F}_{1}$ would be $1 / 2^{\mathrm{n}}$, suggesting $\mathrm{DH}$ breeding is more efficient in selection of recessive gene controlled traits like sterility here; and crossing semi-sterile materials with sterile lines further increased the proportion of highly sterile plants in segregating populations of this study, which has similar effects to backcross with sterile lines (Zhang et al. 1999).

Meanwhile, few effective molecular markers are currently usable for marker assisted selection in sterility (Ru et al. 2015). Consequently, it would take long time to develop a genetically stable TPSGMS line because the expression of sterility in TPSGMS lines needs restricted temperature and light conditions which could be found only once a year (Gu et al. 2002). In our previous breeding program, only two TPSGMS lines K78S and K456S capable of commercial usage were developed by pedigree methods from 1996 to 2010 , while in this study we developed 24 elite TPSGMS lines with complete homozygosity and most desired traits within 4 years by introducing $\mathrm{DH}$ techniques. 
Another issue we address is to identify the better generation for producing DHs. Most breeders prefer to produce $\mathrm{DHs}$ from $\mathrm{F}_{1}$ generation to shorten the breeding cycle, but it may limit the opportunity for recombination (Tadesse et al. 2012). Therefore, producing DHs with selected individuals from $F_{2}$ generation of single crosses or $F_{1}$ generationof pyramiding crosses seems better than that from $F_{1}$ generation of single crosses (Chen et al. 2011). Similarly, Snape and Simpson (1981) were inclined to produce $\mathrm{DHs}$ in barley from $\mathrm{F}_{2}$ generation by comparing the gain in genetic variation for 6 agronomic traits with $\mathrm{DH}$ lines derived from $\mathrm{F}_{1}, \mathrm{~F}_{2}, \mathrm{~F}_{3}$ and intermated $\mathrm{F}_{2}(\mathrm{~S} 3)$ generations. In contrast, lyamabo and Hayes (1995) did not found more favourable genotypes in $\mathrm{DH}$ lines produced from $\mathrm{F}_{2}$ generation than that from $F_{1}$ generation in barley. In present study, the breeding efficiency for sterility was in the order of $F_{3}>F_{2}>F_{1}$, while for finally selected elite sterile lines was $F_{2}>F_{3}>F_{1}$, which seems both $F_{2}$ and $F_{3}$ generations are better for producing $\mathrm{DHs}$ in breeding efficiency. If weighing against the delay and additional cost (lyamabo et al. 1995), producing $\mathrm{DHs}$ from $\mathrm{F}_{2}$ would be the better choice, however, which needs to be further investigated by comparing the breeding efficiency of producing $\mathrm{DHs}$ with the $\mathrm{F}_{1}$ and selected plants of $F_{2}$ and $F_{3}$ derived from the same cross.

DHs produced by $F_{1}$ generation was less successful in breeding efficiency because only one round of recombination occurred and no selection was done, as a result, a high frequency of agronomically undesirable lines were produced (Snap et al. 1981), which was confirmed in this study, most fertile lines discarded came from $F_{1}$ generation. However, it's best in time saving, could be useful for crosses with better predictability and coping with urgent need for developing varieties with resistance to diseases such as yellow rust for its frequently varying pathogenic races.

In this study we developed at least 20 practical TPSGMS lines of wheat that showed stable sterility in two or three years tests, high outcrossing potential and other desirable traits within 4 years, which verified that introducing DH technique is an efficient strategy in developing TPSGMS lines of wheat, both in number and time saving. Generally, producing $\mathrm{DHs}_{\mathrm{s}}$ from $\mathrm{F}_{2}$ generation appears to be the better choice in balance of breeding efficiency and shortening of breeding cycle, however, which should be further confirmed by using materials of different filial generations derived from the same combinations. More practically usable TPSGMS lines would further improve the efficiency of wheat hybrid breeding by increasing the opportunity of developing hybrids with strong heterosis.

\section{References}

Boeven PHG, Würschum T, Rudloff J, Ebmeyer E, Friedrich C, Longin H (2018) Hybrid seed set in wheat is a complex trait but can be improved indirectly by selection for male floral traits. Euphytica 214:110 https://doi.org/10.1007/s10681-018-2188-1.

Chen XM, He ZH, Liu CL, Wang DS, Zhang Y, Jia JZ, Zhang YH (2011) New wheat variety zhongmai 533 developed by wheat $\times$ maize cross. Journal of Triticeae Crops 31: 424-429. 
Ding ML, Zhao H, Gu J, Li HS, Liu K, Yang MJ, Li SX (2017) Research and breeding application progress of the technique of producing double haploid of wheat by wide hybridization between wheat and maize. Agricultural Science and Technology 18: 2202-2208.

Dong PH, Hu YG, Guo GH, He BR, Wang LM, Yuan JG (2012) Inheritance and chromosome location of photoperiod-thermo sensitive male sterility in wheat line Xinong 291S. Plant Breeding 131: 695-699.

Gu J, Yang MJ, Tian YX, Li SX, Zhou JS, Liu K, Yang HX, et al. (2002) Breeding of thermo-photo-sensitive genic male sterile wheat adapted to plateau climates and studies on their fertility in Yunnan. Southwest China Journal of Agricultural Sciences 15: 5-8.

Gu J, Liu K, Li S X, Tian Y X, Yang H X, Shan Q L,Yang M J (2006) Preliminary study on using wheat x maize to induce wheat haploid plant in natural condition of Kunming. Journal of Triticeae Crops 26 (4): $23-26$.

Gu J, Liu K, Li SX, Tian YX, Yang HX, Yang MJ (2008) Study on the in vitro culture of cut plants in wheat haploid embryo induction by a wheat $\times$ maize cross. Frontiers of Agriculture in China 2: 391-395.

Gu J, Yang MJ, Li SX, Tian YX, Li HS, Yang HX, Liu K, et al. (2012) Study on improving frequency of chromosome doubling in wheat haploid produced by wheat $\times$ maize system. Southwest China Journal of Agricultural Sciences 25: 19-21.

Guo RX, Sun DF, Tan ZB, Rong DF, Li CD (2006) Two recessive genes controlling thermo-photoperiod sensitive male sterility in wheat. Theor Appl Genet 112: 1271-1276.

lyamabo OE, Hayes PM (1995) Effects of selection and opportunities for recombination in doubledhaploid populations of barley (Hordeum vulgare L.). Plant Breeding 114: 131-136.

Ji JH, Ru ZG, Zhang GS, Xue X, Ou XQ (2004) Study on pollen fertility and selfed seedset of thermosensitive male sterile wheat line BNY. Journal of Triticeae Crops 24: 24-26.

Kelliher T, Starr D, Su XJ, Tang GZ, Chen ZY, Carter J, Wittich PE et al (2019)One-step genome editing of elite crop germplasm during haploid induction. Nature biotechnology 37:287-292.

Li HS, Li SX, Zhao H, Ding ML, Cui YZ, Gu J, Tian YX, et al. (2015) Effects of glume opening and stigma extertion on outcrossing seed-setting of wheat thermo-photo sensitive genic male sterile lines. Journal of Triticeae Crops 35(12):1671-1675.

Liu K, Li SX, Li HS, Yang MJ, Tian YX, Zhao H, Ding ML, et al. (2016) Effect of simplified emasculation methods on frequency of haploid embryo produced by wheat $\times$ maize cross. Southwest China Journal of Agricultural Sciences 29: 206-208.

Mühleisen J, Piepho HP, Maurer HP, Longin CFH, Reif JC (2013) Yield stability of hybrids versus lines in wheat, barley and triticale. Theor Appl Genet 127:309-316. 
Muqaddas QH, Reif JC, Li Z, Basnet BR, Dreisigacker S, Röder MS (2017) Genome-wide association mapping and genome-wide prediction of anther extrusion in CIMMYT spring wheat. Euphytica 213:73.

Murai K, Tsunewaki K (1993) Photoperiod-sensitive cytoplasmic male sterility in wheat with Aegilops crassa cytoplasm. Euphytica 67: 41-48.

Murai K, Ohta H, Kurushima M, Ishikawa N (2016) Photoperiod-sensitive cytoplasmic male sterile elite lines for hybrid wheat breeding, showing high cross-pollination fertility under long-day conditions. Euphytica 212:313-322.

Niu ZX, Jiang AX, Abu Hammad W, Oladzadabbasabadi A, Xu SS, Mergoum M, Elias EM, et al. (2014) Review of doubled haploid production in durum and common wheat through wheat $\times$ maize hybridization. Plant Breeding 133: 313-320.

Ru ZG, Zhang LP, Hu TZ, Liu HY, Yang QK, Weng ML, Wang B, et al. (2015) Genetic analysis and chromosome mapping of a thermo-sensitive genic male sterile gene in wheat. Euphytica 201:321-327.

Singh SP, Srivastava R, Kumar J (2015) Male sterility systems in wheat and opportunities for hybrid wheat development. Acta Physiologiae Plantarum 37: 1-13.

Snape JW, Simpson E (1981) The genetical expectations of doubled haploid lines derived from different filial generations. Theor Appl Genet 60: 123-128.

Song JY, Carver BF, Powers C, Yan LL, Klápště J, El-Kassaby YA, Chen C (2017) Practical application of genomic selection in a doubled-haploid winter wheat breeding program. Molecular Breeding 37: 117. https://doi.org/10.1007/s11032-017-0715-8.

Suenaga K, Nakajima K (1989) Efficient production of haploid wheat (Triticum aestivum) through crosses between Japanese wheat and maize (Zea mays).. Plant Cell Report 8: 263-266.

Tadesse W, Inagaki M, Tawkaz S, Baum M and Ginkel M (2012) Recent advances and application of doubled haploids in wheat breeding. African Journal of Biotechnology 11: 15484-15492.

Tan CH, Yu GD, Yang PF, Zhang ZH, Pan Y, Zheng J (1992) Preliminary study on sterility of thermo-photosensitive genic male sterile wheat in Chongqing. Southwest China Journal of Agricultural Sciences $5(4): 1-6$.

Tao J, Li SR, Zhou Q, Ren Y, Ou JM, Lei JR, Du XY, et al. (2017) Research progress of thermo-photo sensitive two-line hybrid wheat in Southwest China. Chinese Agricultural Science Bulletin 33:1-8.

Wilson JA, Ross WM (1962) Male sterility interaction of the Triticum aestivum nucleus and Triticum timopheevi cytoplasm. Wheat Information Service 14: 29-30. 
Wang BB, Zhu L, Zhao BB, Zhao YP, Xie YR, Zheng ZG, Li YY et al (2019) Development of a haploidinducer mediated genome editing (IMGE) system for accelerating maize breeding. Molecular Plant12:597-602.

Xiao WJ (2014) Status and trend of hybrid wheat studies in China and abroad. Beijing Agriculture 3: 5860.

Yang MJ, Gu J, Liu K, Li SX, Tian YX, Yang HX, Zhou JS, et al. (2006) Ecological adaptability of thermophoto-sensitive genic male sterile wheat K78S in Yunnan Province. Acta Agronomic Sinica 32: 16181624.

Zhang JJ, Tan CH, Yu GD, Chen H, Shi YM, Li BQ (1999) Application of backcross in developing thermophoto sensitive genic male sterile lines of wheat. Journal of Triticeae Crops, 19(1): 12-13.

Zhang LP, Zhao CP, Shan FH, Zhang FT, Ye ZJ (2007) The mixed genetic analysis of photoperiod temperature sensitive male sterility of BS210 in wheat. Acta Agronomica Sinica 33(9):1553-1557

Zhao CP, Wang X, Zhang FT, Ye ZJ, Dai HJ (1999) Status of hybrid wheat research and two-line system based on photo-thermo sensitive genic male sterility. Beijing Agricultural Sciences 17(2):3-5. (in Chinese)

Zhao CP (2010) Status and trends of hybrid wheat research in China. Journal of Agricultural Science and Technology $12(2): 5-8$.

\section{Declarations}

Acknowledgements The work was supported by the National Key Research and Development Program of China (2016YFD0101603); the Director Fund of Institute of Food Crops, Yunnan Academy of Agricultural Sciences (2013LZS003); the Talent Young Scientist Program of Ministry of Science and Technology of China; and Talent Cultivation Program of Yunnan Academy of Agricultural Sciences.

\section{Conflict of interest}

Authors declare no conflict of interest.

\section{Author contributions}

HS Li and SX Li conceived and designed the research; S Abdelkhalik, A Shahzad, J Gu and H Zhao performed the experiments; MJ Yang and HS Li wrote the manuscript; ML Ding and K Liu contributed to preparation of the manuscript; All the authors read and approved the manuscript.

\section{Tables}


Figures

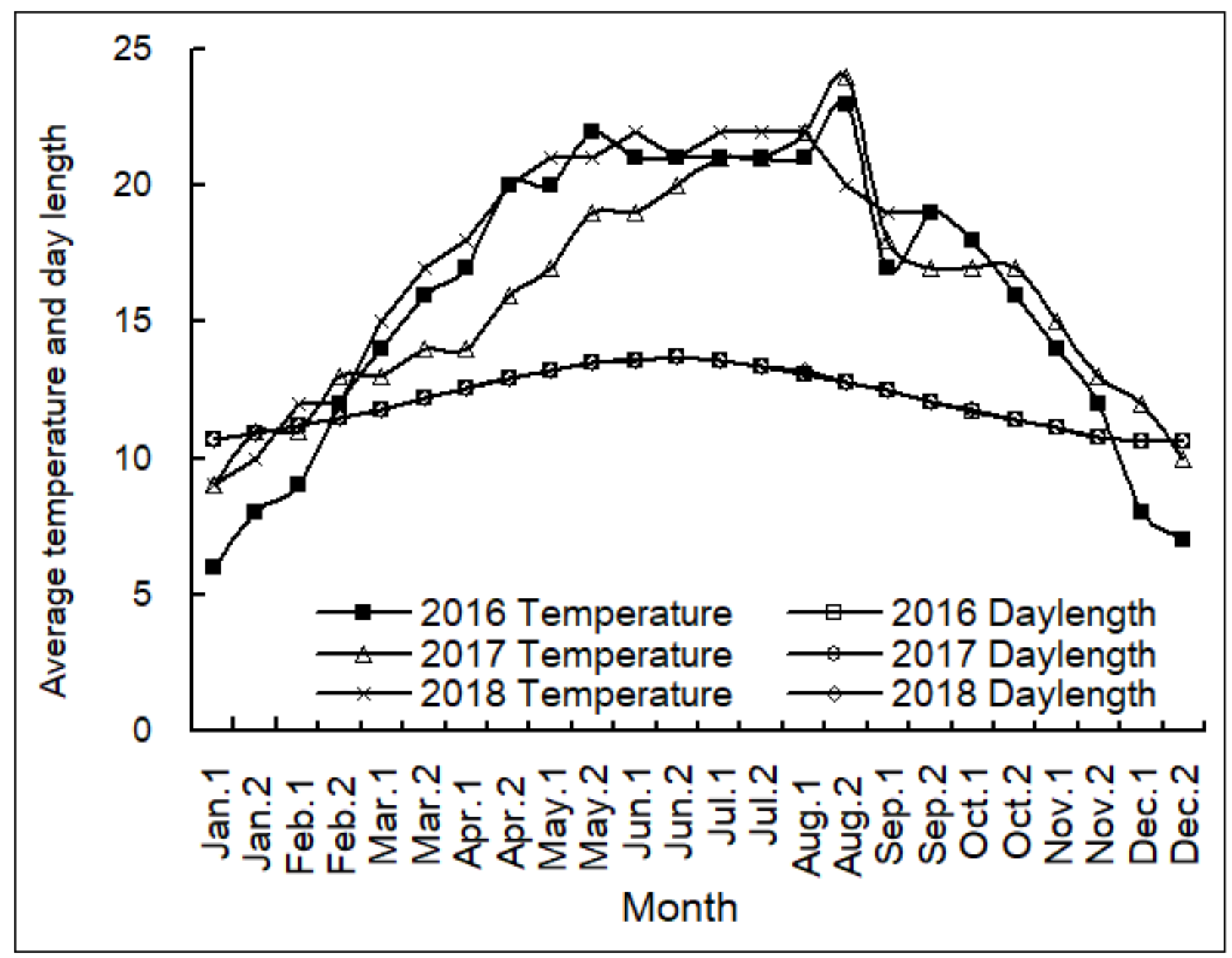

Figure 1

Daily average temperature and day length around the year during 2016-2018. Jan.1 means the first half of the January, Jan. 2 means the second half of the January, the same as that of other months. $\square, \otimes, x$ :

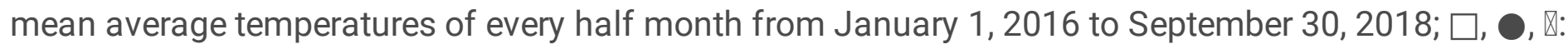
mean average daylengths of every half month during the same periods. 


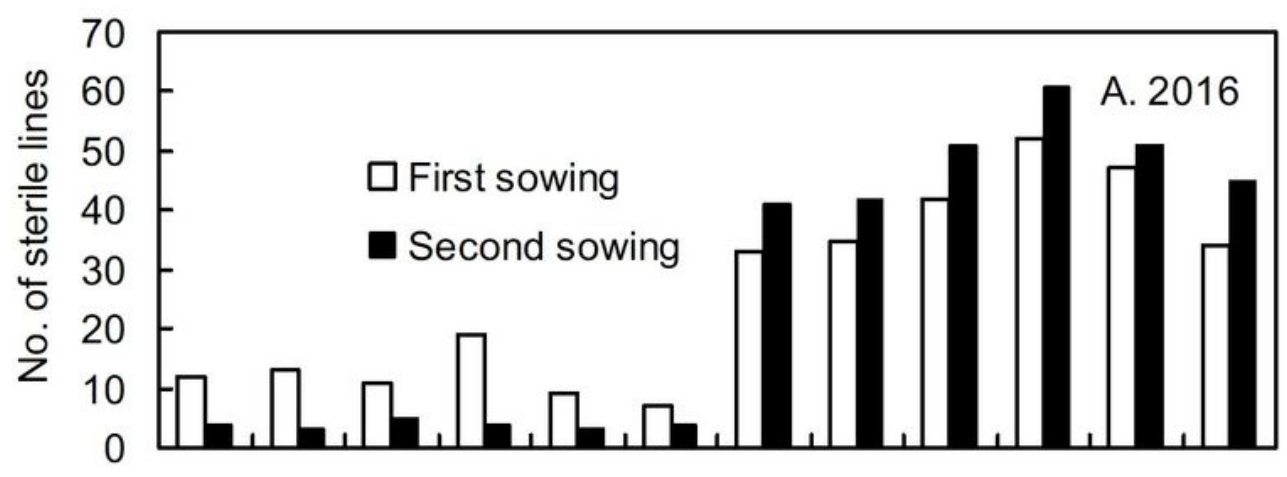

$\begin{array}{llllllllllll}0 & 0-1 & 1-2 & 2-3 & 3-4 & 4-5 & 5- & 10- & 20- & 30- & 50-70-\end{array}$ Seed setting rate(\%) $10 \quad 20 \quad 30 \quad 50 \quad 70 \quad 90$
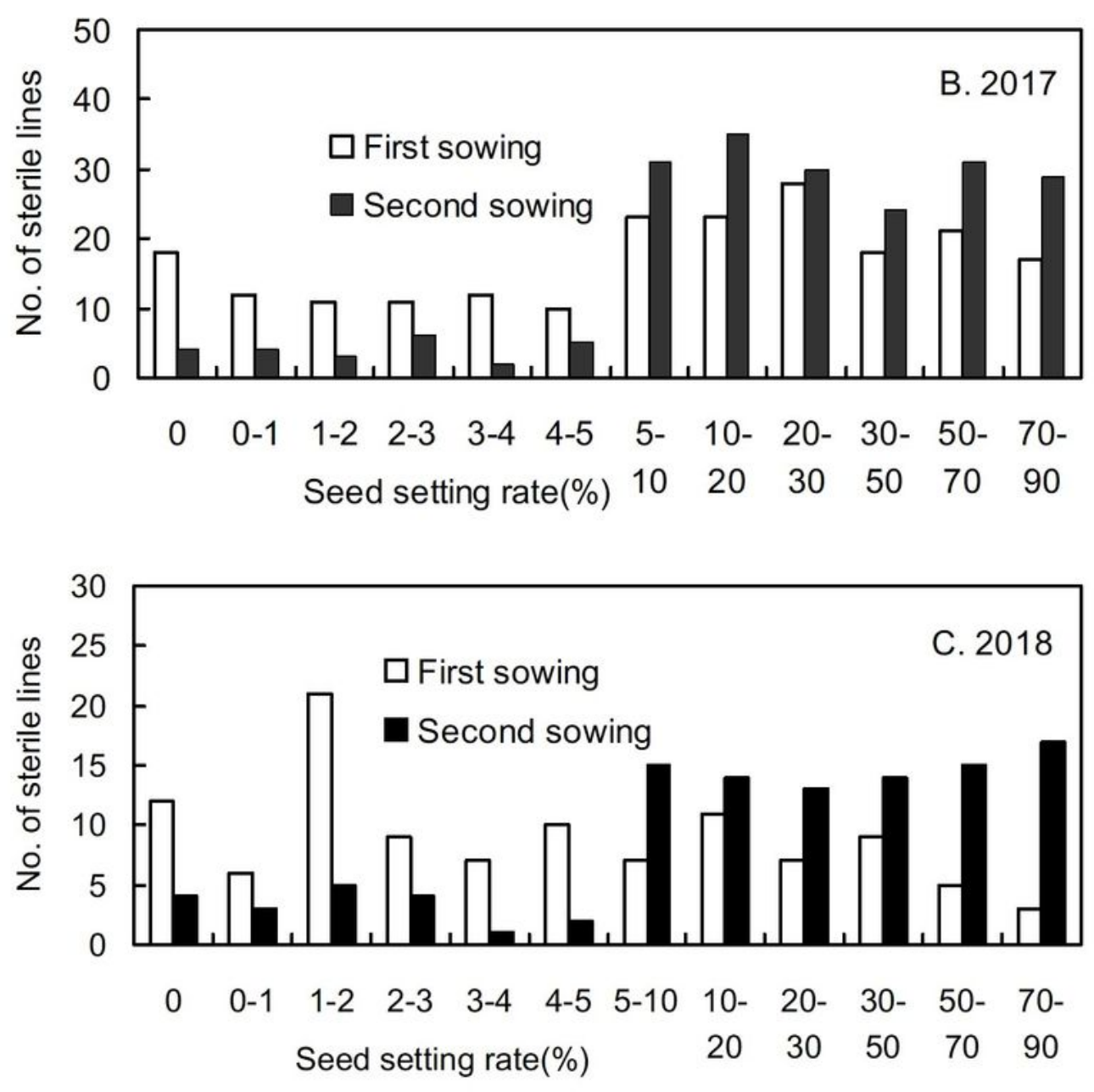

Figure 2

Seed setting rate distribution in first and second sowings of 314 DH lines in 2016 (A), 204 DH lines in 2017 (B), and 107 DH lines in 2018. First and second sowing dates: October 15 and November 20 of every year, respectively. 


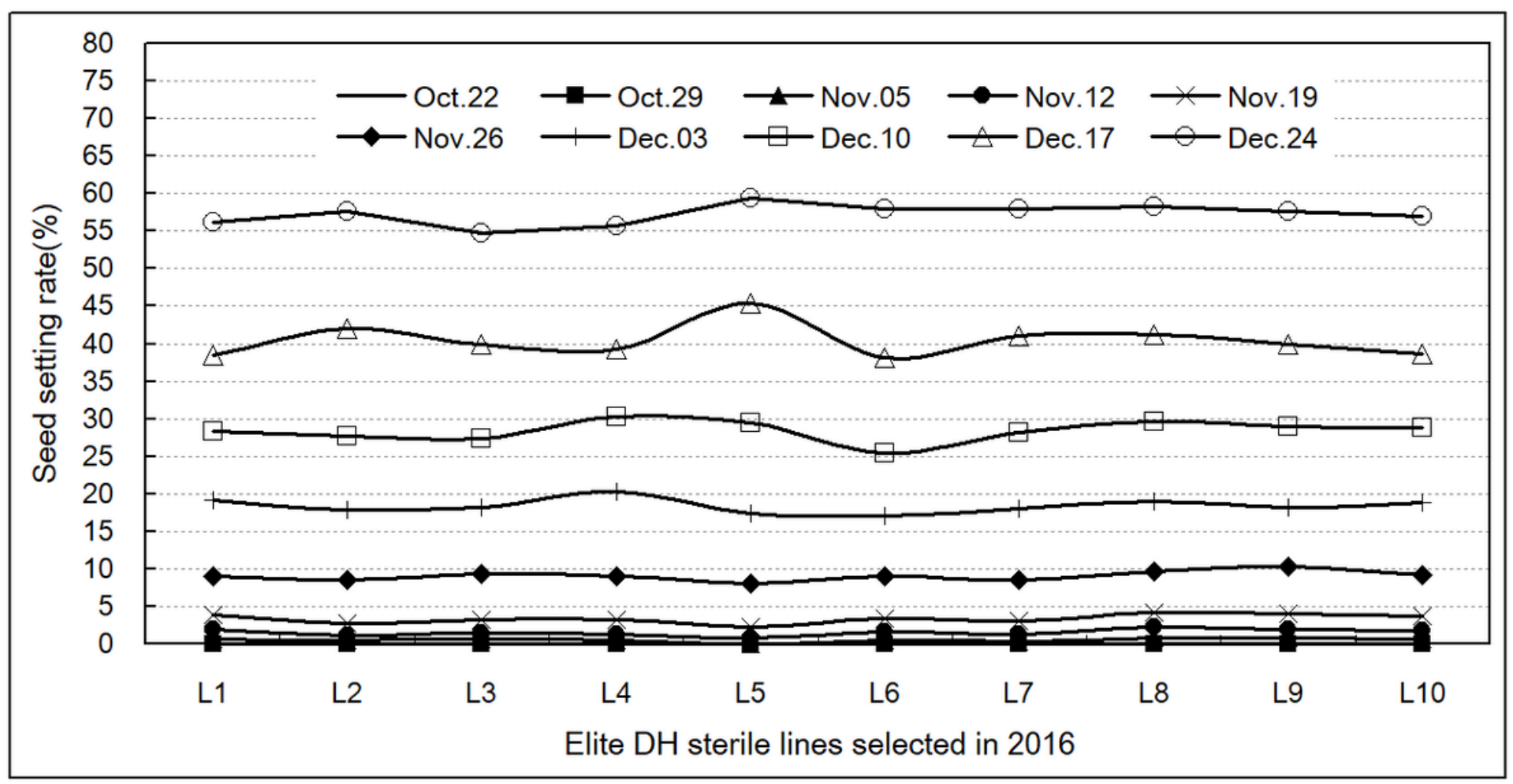

Figure 3

Seed setting rates of ten elite TPSGMS lines in ten sowings of 2017/2018 cycle. Sowing dates started from October 22, 2017 with interval of seven days.

\section{Supplementary Files}

This is a list of supplementary files associated with this preprint. Click to download.

- SupplementalFigure1.xls

- table4.doc

- table1.doc

- SupplementalFigure2.xls

- SupplementalFigure3.xls

- table7.doc

- table5.doc

- table3.doc

- table2.doc

- table6.doc 